Federal Reserve Bank of Minneapolis

Research Department

\title{
If Exchange Rates Are Random Walks Then Almost Everything We Say About Monetary Policy Is Wrong
}

\author{
Fernando Alvarez, Andrew Atkeson, \\ and Patrick J. Kehoe*
}

Working Paper 650

March 2007

\begin{abstract}
*Alvarez, University of Chicago and National Bureau of Economic Research, email: f-alvarez1@uchicago.edu; Atkeson, University of California-Los Angeles, Federal Reserve Bank of Minneapolis, and National Bureau of Economic Research, email: andy@atkeson.net; Kehoe, Federal Reserve Bank of Minneapolis, University of Minnesota, and National Bureau of Economic Research, email: pkehoe@res.mpls.frb.fed.us. The authors thank the National Science Foundation for financial assistance and Kathy Rolfe and Joan Gieseke for excellent editorial assistance. The views expressed herein are those of the authors and not necessarily those of the Federal Reserve Bank of Minneapolis or the Federal Reserve System.
\end{abstract}


The key question asked of standard monetary models used for policy analysis is, How do changes in short-term interest rates affect the economy? The standard answer built into these models is that such policy changes affect the economy by changing the means of macroeconomic aggregates and having no effect on their conditional variances. Unfortunately, the data on exchange rates imply nearly the opposite: Fluctuations in interest rates are associated with nearly one-forone changes in conditional variances and nearly no changes in conditional means. With regard to monetary policy analysis, this means that standard monetary models capture essentially nothing of what is going on in the data. Therefore, almost everything we say about monetary policy based these models is wrong.

Standard log-linear models of monetary policy of both the New Keynesian and neoclassical variety link nominal interest rates, through an Euler equation, to the conditional means of the log of two variables: the representative agent's marginal utility growth and inflation. (Changes in these two variables are loosely thought of as reflecting the real and nominal effects of monetary policy.) The main debate among standard modelers has been about how much interest rate changes affect each of the two variables. They don't debate a common assumption of their models, that interest rate changes have no effect on the conditional variances of marginal utilities and inflation.

That common assumption, however, is grossly inconsistent with a well-established feature of the data: nominal rates of exchange between major currencies are well-approximated by random walks. ${ }^{1}$ Mechanically, that fact implies that when a central bank changes its interest rate relative to the rates on other major currencies, the change is reflected almost entirely as changes in the excess returns on its bonds over the returns on foreign bonds. Interpreted in a standard model the exchange rate fact implies that changes in a domestic interest rate relative to a foreign interest rate lead to one-for-one changes in conditional variances and nearly no changes in conditional means. The fact thus implies that, at least when they are analyzing changes in domestic interest rates relative to those of foreign interest rates, standard monetary models are of little use.

Clearly, to analyze monetary policy, we need a new approach that captures the effects of interest rate changes on conditional variances. We have tried one such approach in which such effects are interpreted as time-varying risk. (For elaboration, see Fernando Alvarez et al., 2006.)

\section{Standard Models of Monetary Policy}

Standard models of monetary policy start with a presumption that a monetary authority controls the short-term nominal interest rate on bonds, or other assets, denominated in its own currency. Most of these models assume a representative consumer who participates in all asset markets. We begin by describing these representative consumer models and their assumption that 
interest rate changes affect only the conditional means of variables. Then we show how that description generalizes beyond those models.

\section{A. Representative Consumer Models}

The short-term nominal interest rate enters standard representative consumer models through an Euler equation of the form

$$
\frac{1}{1+\mathrm{i}_{t}} \equiv \exp \left(-i_{t}\right)=\beta E_{t}\left[\frac{U_{c t+1}}{U_{c t}} \frac{1}{\pi_{t+1}}\right]
$$

where $i_{t}$ is the logarithm of the short-term nominal interest rate $1+\mathrm{i}_{t}, \beta$ and $U_{c t}$ are the discount factor and the marginal utility of the representative consumer, and $\pi_{t+1}$ is the inflation rate. Analysts then commonly assume that the data are well-approximated by a conditionally log-normal model, so that this Euler equation can be written as

$$
i_{t}=E_{t}\left[-\log \frac{U_{c t+1}}{U_{c t}} \frac{1}{\pi_{t+1}}\right]-\frac{1}{2} \operatorname{var}_{t}\left[\log \frac{U_{c t+1}}{U_{c t}} \frac{1}{\pi_{t+1}}\right]
$$

The critical question in monetary policy analysis is what terms on the right side of (2) change when the monetary authority changes the interest rate $i_{t}$. The standard assumption is that the conditional variances are constant, so that the second term in (2) is constant. This leaves the familiar version of the Euler equation:

$$
i_{t}=-E_{t} \log \frac{U_{c t+1}}{U_{c t}}+E_{t} \log \pi_{t+1}+\text { constant. }
$$

Changes in the nominal interest rate can thus be broken down into the change in the expected growth in the marginal utility of consumption of the representative agent and the change in expected inflation. Loosely speaking, we think of the first component as reflecting the real effect of monetary policy on the economy and the second as reflecting the nominal effect. The debate in monetary policy analysis is over how changes in the nominal interest rate are divided into these two types of effects. For example, in the simplest flexible price models, monetary policy is neutral, its real effects are zero, and changes in nominal interest rates change only expected inflation. In more complicated models, frictions of various sorts, such as sticky prices, imply that changes in interest rates have both real and nominal effects, and the details of the model determine their decomposition.

Regardless of which side of the debate a particular standard model of monetary policy represents, however, it assumes that changes in interest rates affect only the conditional means of endogenous variables, not conditional variances or other higher moments. This, as we shall see, is 
a serious problem for representative consumer models.

\section{B. More General Models}

More general models, which do not assume a representative consumer, also have this problem, for they, too, limit the effects of monetary policy changes to the conditional means of variables.

To see this, note that equations (1)-(3) can be written more abstractly in terms of a nominal pricing kernel (or stochastic discount factor) $m_{t+1}$ as

$$
\exp \left(-i_{t}\right)=E_{t} m_{t+1}
$$

In a model with a representative agent, this pricing kernel is $m_{t+1}=\beta U_{c t+1} /\left(U_{c t} \pi_{t+1}\right)$ and (4) is the representative agent's first-order condition for optimal bond holdings. In some segmented market models, (4) is the first-order condition for agents who participate in the bond market, while in others, (4) is no single agent's first-order condition. In general, equation (4) is implied by lack of arbitrage possibilities in the financial market. With log-normality, (4) implies that

$$
i_{t}=E_{t}\left[-\log m_{t+1}\right]-\frac{1}{2} \operatorname{var}_{t}\left[\log m_{t+1}\right]
$$

and, with constant conditional variances, that $i_{t}=-E_{t} \log m_{t+1}+$ constant. Thus, the more general assumption made in the literature is that monetary policy affects only the conditional mean of the log of the pricing kernel, not its conditional variance.

\section{Adding a Foreign Country}

Below we use data on interest rate differentials and exchange rates to flesh out the major problem with the standard approach. Here, to set up that analysis, we consider the implications of adding to our model a foreign country with its own currency and its own monetary policy.

Assuming conditional log-normality gives the foreign analog of (5), namely, that

$$
i_{t}^{*}=E_{t}\left[-\log m_{t+1}^{*}\right]-\frac{1}{2} \operatorname{var}_{t}\left[\log m_{t+1}^{*}\right]
$$

where asterisks denote foreign variables. When the foreign pricing kernel comes from a representative consumer in the foreign country, $m_{t+1}^{*}=\beta U_{c t+1}^{*} /\left(U_{c t}^{*} \pi_{t+1}^{*}\right)$ and (6) is the foreign representative consumer's Euler equation for foreign bonds.

Combining (5) and (6) gives that the interest differential can be written as

$$
i_{t}-i_{t}^{*}=E_{t}\left[\log m_{t+1}^{*}-\log m_{t+1}\right]-p_{t},
$$


where

$$
p_{t}=\frac{1}{2}\left[\operatorname{var}_{t} \log m_{t+1}^{*}-\operatorname{var}_{t} \log m_{t+1}\right] .
$$

Note that under the standard assumption of constant conditional variances, the term $p_{t}$ is constant. (For a similar derivation, see David K. Backus et al., 2001.)

The standard approach to analyzing monetary policy thus simply assumes that when the monetary authorities in two countries change the interest differential $i_{t}-i_{t}^{*}$, what changes are the conditional means in (7), not the conditional variances in (8).

\section{The Problem}

The problem is that the data contradict that assumption. One of the most robust features of the data on nominal exchange rates between major currencies is that they are well-approximated by random walks. This fact means that the standard models have the analysis backwards: when the interest differential changes, what changes are not the conditional means but the conditional variances.

\section{A. A Contradiction}

We demonstrate how the data contradict the standard model by linking exchange rates to nominal pricing kernels. Lack of arbitrage and complete financial markets imply that

$$
m_{t+1}^{*}=m_{t+1} \frac{e_{t+1}}{e_{t}}
$$

where $e_{t}$ is the nominal exchange rate. To derive this equation in a standard model, add into that model the opportunity for a home investor to purchase a foreign currency-denominated asset with stochastic return $R_{t+1}^{*}$. The home currency return on this asset is given by $R_{t+1}^{*} e_{t+1} / e_{t}$; hence, lack

of arbitrage for the home investor implies that $1=E_{t} m_{t+1} \frac{e_{t+1}}{e_{t}} R_{t+1}^{*}$. The pricing kernel $m_{t+1}^{*}$ defined by (9) thus also prices foreign currency returns, so that $1=E_{t} m_{t+1}^{*} R_{t+1}^{*}$. Under the assumption of complete markets, the pricing kernel is unique, and this gives the result (9). The assumption of complete markets is sufficient to obtain this result, but it is by no means necessary, as we discuss below.

Taking logs and then conditional expectations of (9) gives that

$$
E_{t} \log e_{t+1}-\log e_{t}=E_{t} \log m_{t+1}^{*}-E_{t} \log m_{t+1} .
$$

Using (10) in (7) gives that

$$
i_{t}-i_{t}^{*}=E_{t}\left[\log e_{t+1}-\log e_{t}\right]-p_{t},
$$


where, recall, $p_{t}$ represents an expression involving the conditional variances.

Now compare equation (11) to the data. In the data, interest differentials show large and persistent movements over time. But since exchange rates are well-approximated by random walks, the expected change in the exchange rate, $E_{t}\left[\log e_{t+1}-\log e_{t}\right]$, must be approximately a constant. ${ }^{2}$ Hence, (10) and (11) imply that when the interest differential $i_{t}-i_{t}^{*}$ moves, what moves are the conditional variances in $p_{t}$, not the conditional means in (10).

Why should this discrepancy trouble users of standard monetary models? Because it reveals that their standard debates about how to divvy up the effects of interest rate changes into real and nominal effects are debates about terms that are essentially constant. The standard monetary models, that is, have nothing to say about the terms that are actually affected by interest rate changes, the conditional variances.

\section{B. An Interpretation}

Changes in conditional variances are abstract model expressions, but they can be interpreted as critical economic variables: changes in risk premia. Under this interpretation, what standard models are missing is a link between monetary policy changes and risk.

To understand this interpretation, consider a simple example. Let the foreign currency be the U.K. pound and the home currency, the U.S. dollar. Define the (log) excess return for a pounddenominated bond as the expected log dollar return on a pound bond minus the log dollar return on a dollar bond. Let $\exp \left(i_{t}\right)$ and $\exp \left(i_{t}^{*}\right)$ be the nominal interest rates on the dollar and pound bonds and $e_{t}$, the price of pounds in units of dollars, or the exchange rate between the currencies, in a time period $t$. The dollar return on a pound bond, $\exp \left(i_{t}^{*}\right) e_{t+1} / e_{t}$, is obtained by converting a dollar in period $t$ to $1 / e_{t}$ pounds, buying a pound bond paying interest $\exp \left(i_{t}^{*}\right)$, and then converting the resulting pounds back to dollars in $t+1$ at the exchange rate $e_{t+1}$. The $(\log )$ excess expected return $p_{t}$ is then defined as the difference between the expected log dollar return on a pound bond and the log return on a dollar bond:

$$
p_{t}=i_{t}^{*}+E_{t} \log e_{t+1}-\log e_{t}-i_{t} .
$$

Clearly, the dollar return on the pound bond is risky, because the future exchange rate $e_{t+1}$ is not known in $t$. The excess return compensates the holder of the pound bond for this exchange rate risk.

In the model that we have laid out, the excess expected return $p_{t}$ in (12) can be expressed in terms of conditional variances of nominal pricing kernels, as in (8). Hence, we interpret changes in these conditional variances as changes in risk. (Other possible interpretations of $p_{t}$ are that it 
represents compensation to the holder of the foreign bond for differences in liquidity services or transaction costs or tax rates, none of which are measured across these bonds.)

With our interpretation, we can restate our point: the fact that exchange rates are approximately random walks implies that most of the fluctuations in interest rate differentials are changes in risk - a feature standard models do not link to monetary policy changes.

\section{Extensions}

We can extend our argument a step further. So far, in order to derive equation (9), the link between exchange rates and nominal pricing kernels, we have assumed complete asset markets. Here we show how our argument extends to models with incomplete markets and to models with other financial frictions.

Consider, first, simple incomplete market models which allow the trading of only a limited set of financial assets. In such models, pricing kernels are not unique. As discussed by Michael W. Brandt et al. (2006), however, even with incomplete markets, equation (9) holds for the minimum variance pricing kernels. Hence, with such kernels, our argument goes through unchanged.

Consider next a version of our argument that applies even if asset markets are extremely incomplete, for example, if a home consumer has access to only three assets: a home currency bond, a foreign currency bond, and foreign currency. We show that in such a situation, if the exchange rate is a random walk, then fluctuations in interest differentials correspond to fluctuations in conditional variances and covariances, not to fluctuations in conditional means.

To see that, let $m_{t+1}$ now be any kernel that prices home currency returns. This kernel must satisfy $1=E_{t} m_{t+1} R_{t+1}$ for any asset with the home currency return $R_{t+1}$ at $t+1$. In particular, the kernel must satisfy (4) for home currency bonds and $1=E_{t} m_{t+1}\left(e_{t+1} / e_{t}\right) \exp \left(i_{t}^{*}\right)$ for the home currency return on an investment in foreign currency bonds. With some simple manipulations, conditional log-normality of all variables implies that

$$
i_{t}-i_{t}^{*}=\left[E_{t} \log e_{t+1}-\log e_{t}\right]+\left[\frac{1}{2} \operatorname{var}_{t}\left(\log \frac{e_{t+1}}{e_{t}}\right)+\operatorname{cov}_{t}\left(\log m_{t+1}, \log \frac{e_{t+1}}{e_{t}}\right)\right]
$$

If exchange rates are random walks, then the first term on the right side of (13) is constant. So fluctuations in interest differentials must lead to one-for-one changes in the second term. Hence, again, changes in monetary policy are shown by the data to be changes in conditional variances whereas the standard models assume they are changes in conditional means. Thus, our argument applies even for extensions of standard models that include extreme forms of market incompleteness.

Our argument applies more generally as well, to the large class of models with financial 
frictions in which the pricing kernels satisfy equation (9) and which assume that the conditional variances of these pricing kernels are constant.

\section{Implications}

Our analysis of the standard approach to modeling monetary policy tells us, of course, that economists need new models, and we have some suggestions for how to get them. Our analysis also has something to say, however, about how U.S. monetary policy has worked in recent years. And it implies as well that the old standard models need not be discarded completely; they can still help us understand cross section patterns of average short-term interest differentials.

\section{A. Arguing Causality}

In making our point, we have not yet needed to argue the direction of causality between changes in interest rates and changes in risk. Does risk in financial markets change for some reason unrelated to monetary policy, and the monetary authority react, changing the nominal interest rate in order to accommodate the risk change? Or does the monetary authority's interest rate change result in a change in financial market risk? With our exchange rate analysis in mind, a brief review of recent U.S. and U.K. monetary policy suggests that at least lately the causality has been from changes in interest rates to changes in risk premia. ${ }^{3}$

A graphical view of the recent monetary policies of the two countries suggests this. Figure 1A plots monthly data on the U.S. federal funds rate and the Bank of England's official bank rate from January 2000 through November 2006. In this figure, we clearly see the Federal Reserve's decision to dramatically reduce the federal funds rate over the first half of this time period and then to raise it over the second half. The corresponding policy moves by the Bank of England were much less dramatic. The figure shows that these differences in monetary policy between the United States and the United Kingdom led to large and persistent movements in the interest differential between the dollar and the pound. Market observers have attributed these policy decisions to a variety of factors, none of which include accommodating changes in the conditional volatility of consumption growth or inflation or, more generally, in pricing kernels.

The interest differential movements do not correlate well with changes in exchange rates over this period. Figure 1B is a scatterplot of the dollar-pound interest differential, $i_{t}-i_{t}^{*}$, against the corresponding change in exchange rates, $\log e_{t+1}-\log e_{t}$, with both series expressed in annualized units. $^{4}$ The widely dispersed plots are consistent with the idea that the expected change in the dollar-pound exchange rate was essentially unrelated to the dollar-pound interest differential over this time period.

If we accept that monthly exchange rate changes are unrelated to interest rate differentials, 
then together the two graphs of Figure 1 indicate that at the beginning of 2004, investors required an expected excess return of almost three percentage points to hold British pounds, while at the beginning of 2006, that requirement was zero. Figure 1 thus seems to imply that recent U.S. monetary policy actions have had their main impact on risk and not on the factors that standard analyses focus on.

\section{B. Using Old Models}

We have argued that the standard models for monetary policy analysis are not useful for understanding how fluctuations in interest differentials affect the economy. Are these models useful at all? The data suggest that they are. Standard models do a reasonable job of accounting for cross-section data on long-run averages of differences in interest rates across countries.

To investigate this issue, we use monthly data for the period from January 1976 to March 1998 to construct average one-month interest rate differentials with the U.S. rate for 14 countries as well as corresponding average rates of exchange rate change over this period. Figure 2 displays a scatterplot of these data. It shows a clear positive relationship between the averages, with slope close to 1 . This relationship supports the idea that regardless of its problem with monetary policy analysis, the standard model with constant conditional variances is a reasonable approximation for cross-section data on long averages of differences in short-term interest rates across countries.

\section{Designing New Models}

The data on exchange rates push us to the view that analysts of monetary policy must look in new directions for tools to help us understand how policy changes affect the economy. One possibly fruitful direction is to develop models in which the excess return on foreign bonds fluctuates at the monthly level due to fluctuations in differential liquidity services, differential transaction costs, or differential tax rates across bonds. A more promising direction is simpler: to develop models in which changes in monetary policy affect the economy primarily by changing risk. In ongoing research (in Alvarez et al., 2006), we have built such a model based on the idea that asset markets are segmented and that monetary policy affects risk by endogenously changing the degree of market segmentation. We have shown that this model can generate, qualitatively, the type of systematic variation in risk premia called for by the data on interest rates and exchange rates. Our work, of course, represents only a first, simple step toward building models in which changes in monetary policy affect the economy primarily by changing risk.

\section{Concluding Remarks}

Must monetary models be able to account for fluctuations in excess returns? Indeed, hasn't modern business cycle theory been quite successful at accounting for fluctuations in aggregate 
quantities even though it has done a fairly miserable job at accounting for asset prices, particularly the large movements in excess returns that are part of asset prices? This sort of scepticism is implicit in much of the business cycle literature. Accounting for asset prices seems to be thought of as of second-order importance when thinking about the determination of economic aggregates such as consumption, investment, and employment, which are at the heart of business cycle theory.

Regardless of the merits of that view, it is inappropriate for analyzing monetary policy. Determining how changes in an asset price, the short-term interest rate, affects the economy is clearly at the heart of monetary policy analysis. As we have argued, the data on exchange rates imply that movements in interest rate differentials are reflected almost entirely in fluctuations in excess returns. Thus, for monetary policy, accounting for fluctuations in these excess returns is essential, and monetary models which cannot account for them cannot help us understand the effects of interest rate changes on the economy.

We have used data on exchange rates to rethink the analyses of interest rate changes in standard monetary models. We could instead have used data on the excess returns on long-term domestic bonds over short-term domestic bonds, since another well-established fact is that these excess returns vary systematically with variables plausibly controlled by the Federal Reserve, such as the term spread. In standard models, however, these excess returns are all constant. These models thus cannot account for term spread movements either.

We have focused on exchange rates rather than the term structure of interest rates because the implications of exchange rates are so striking. Specifically, if exchange rates are random walks, then all of the fluctuations in interest differentials are accounted for by fluctuations in conditional variances and none by fluctuations in conditional means. The data are so opposite of what standard models assume that even the most die-hard defenders of them should take note: If these data are accurate, then almost everything we say about monetary policy is wrong. 


\section{Notes}

${ }^{1}$ This finding dates back at least to the work of Richard A. Meese and Kenneth Rogoff (1983) and has been recently been confirmed by Yin-Wong Cheung et al. (2005). As discussed in Cheung et al. (2005), some evidence suggests that exchange rates are not exactly random walks, but rather predictable, at least at long horizons.

${ }^{2}$ Indeed, in a large literature, at least since Eugene F. Fama's (1984) seminal work, this conditional expectation has been found to comove negatively with interest differentials. In particular, in a regression of the form $\log e_{t+1}-\log e_{t}=a+b\left(i_{t}-i_{t}^{*}\right)+\varepsilon_{t}$, the estimated value of $b$ is almost always smaller than one and is often negative. A negative value of $b$ strengthens our argument, but for simplicity, we focus on what happens with $b=0$, or when the exchange rate is a random walk.

${ }^{3}$ There have been other episodes in which observers have argued that the Federal Reserve has changed policy in response to changes in financial market risk. These include the stock market crash of October 1987, the Russian debt crisis in 1998, and the period after September 11, 2001.

${ }^{4}$ The difference between the U.S. federal funds rate and the U.K. official bank rate is nearly identical to the interest differential relevant for exchange rate arbitrage, namely, the one-month dollar-pound forward premium. 


\section{References}

Alvarez, Fernando, Andrew Atkeson, and Patrick J. Kehoe. 2006. "Time-Varying Risk, Interest Rates, and Exchange Rates in General Equilibrium.” Federal Reserve Bank of Minneapolis Research Department Staff Report 371.

Backus, David K., Silverio Foresi, and Chris I. Telmer. 2001. "Affine Term Structure Models and the Forward Premium Anomaly." Journal of Finance, 56 (1): 279-304.

Brandt, Michael W., John H. Cochrane, and Pedro Santa-Clara. 2006. "International Risk Sharing Is Better Than You Think, or Exchange Rates Are Too Smooth." Journal of Monetary Economics, 53 (4): 671-98.

Cheung, Yin-Wong, Menzie D. Chinn, and Antonio Garcia Pascual. 2005. "Empirical Exchange Rate Models of the Nineties: Are Any Fit to Survive?" Journal of International Money and Finance, 24 (7): 1150-75.

Fama, Eugene F. 1984. "Forward and Spot Exchange Rates." Journal of Monetary Economics, 14 (3): 319-38.

Meese, Richard A., and Kenneth Rogoff. 1983. "Empirical Exchange Rate Models of the Seventies: Do They Fit Out of Sample?" Journal of International Economics, 14 (1-2): 3-24. 
Figure 1. Evidence That Recent U.S. Monetary Policy Changes Have Changed Financial Market Risk

Figure 1A. U.S. Policy Changed More Dramatically Than Britain's

U.S. Federal Funds Rate and U.K. Official Bank Rate

Monthly, January 2000-November 2006

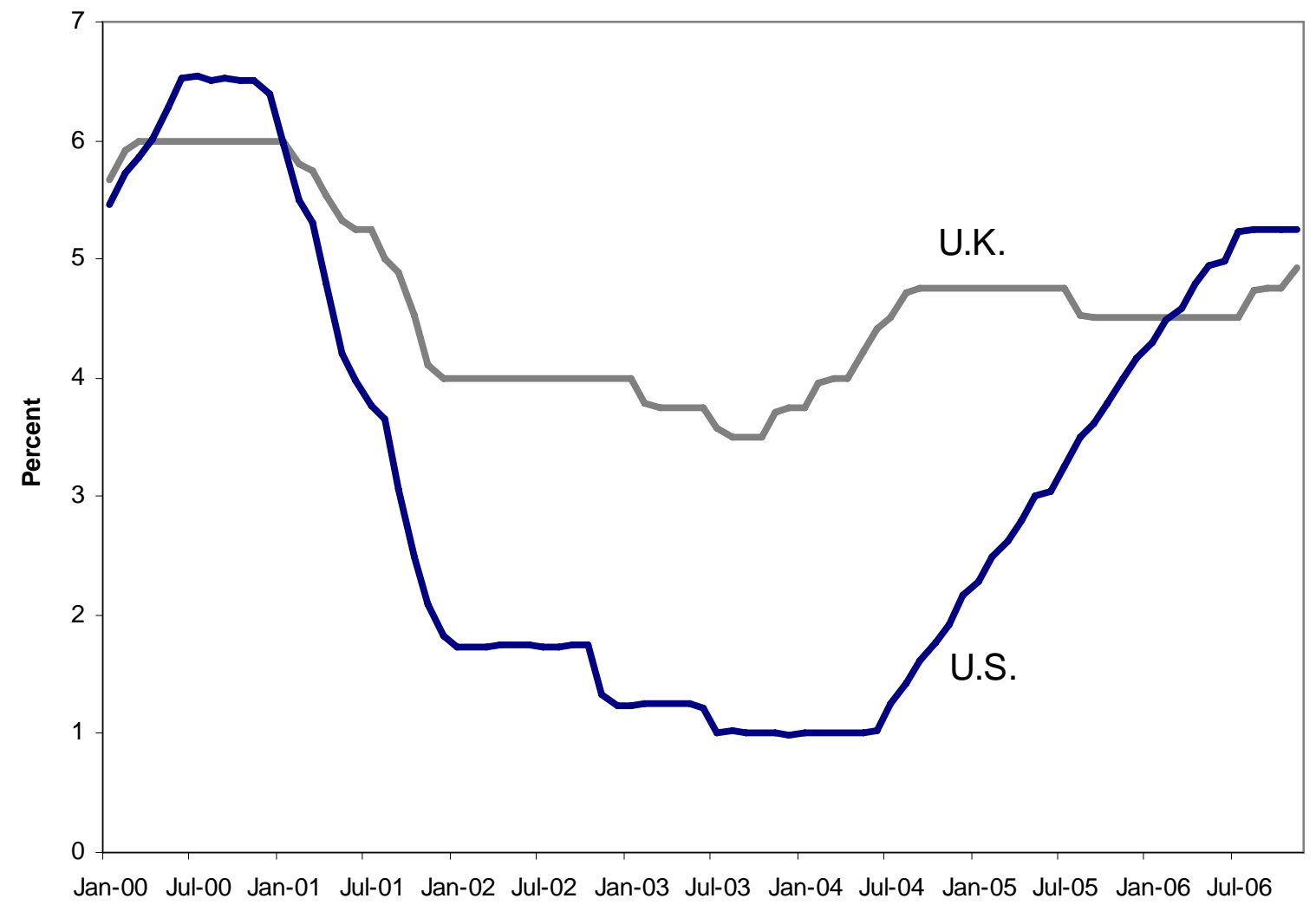

Sources: U.S. Federal Reserve Board of Governors, Bank of England 
Figure 1B. The Policy Difference Was Not Related to Changes in Exchange Rates

U.S. and U.K. Interest Rate Differential vs. Exchange Rate Change Annualized, 2000-2006

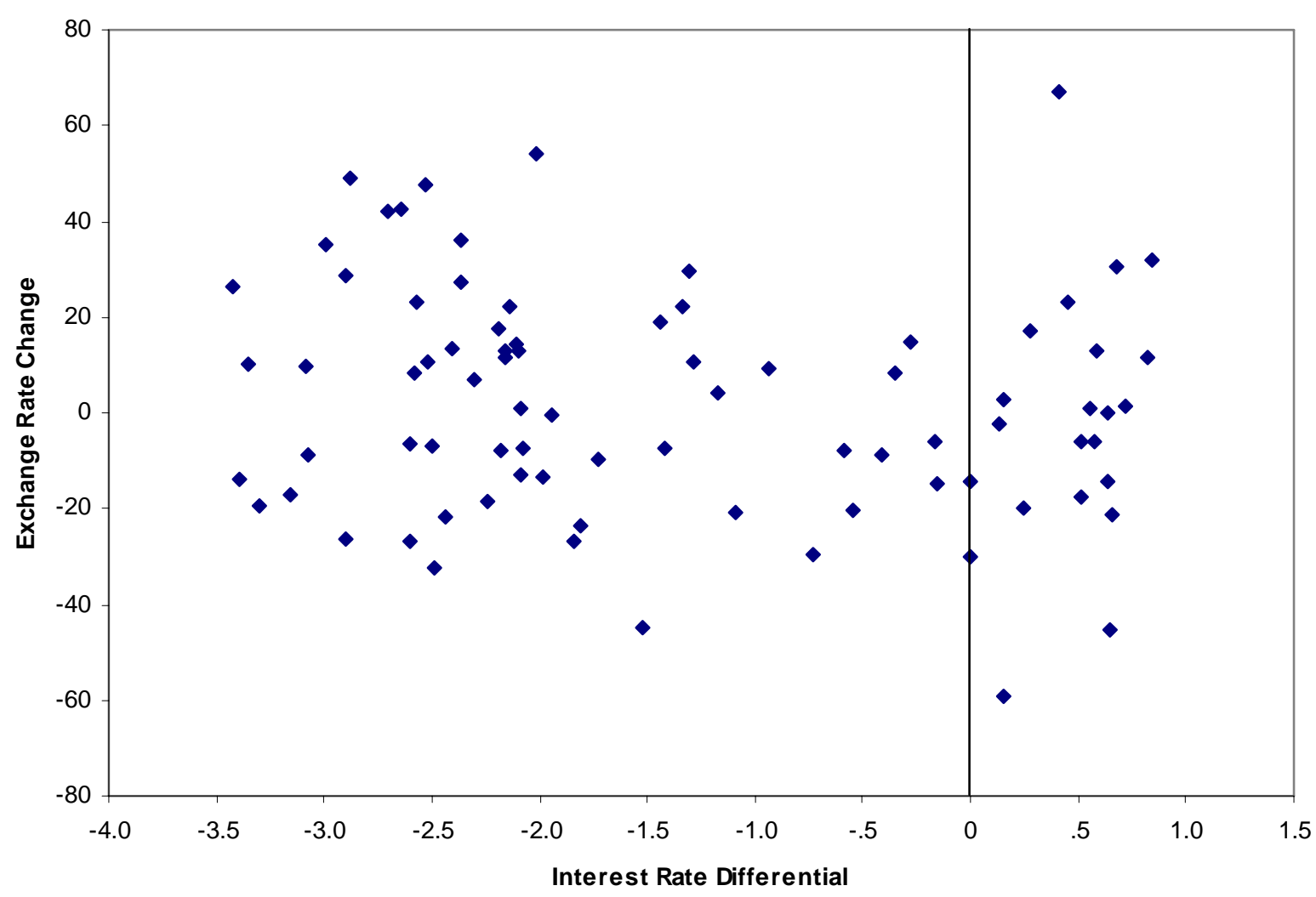

Sources: U.S. Federal Reserve Board of Governors, Bank of England 


\section{Figure 2. Standard Models Can Account for Some Long-Run Interest Rate Differences Across Countries}

Average One-Month Interest Rate Differential (With U.S.) vs.

Average One-Month Change in Exchange Rate (With U.S. Dollar)

January 1976-March 1998, for 14 Countries*

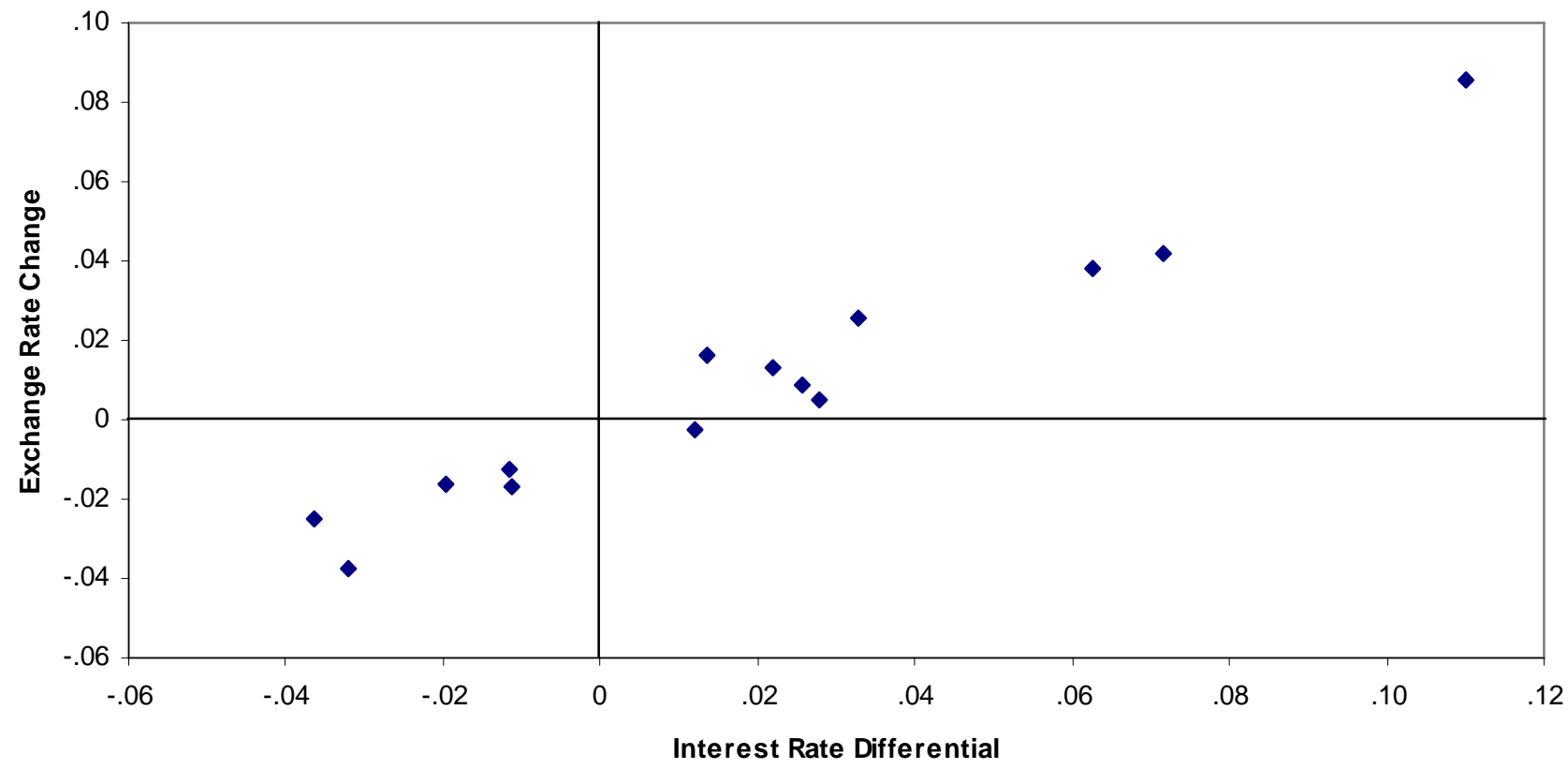

*The countries are Austria, Belgium, Canada, Denmark, England, France, Germany, Italy, Japan, the Netherlands, Portugal, Spain, Sweden, and Switzerland.

Sources: Ravi Bansal and Magnus Dahlquist 